\title{
Mapping Chestnut Stands Using Bi-Temporal VHR Data
}

\author{
Francesca Marchetti ${ }^{1, *}$, Björn Waske ${ }^{2}$, Manuel Arbelo ${ }^{1}{ }^{(D}$, Jose A. Moreno-Ruíz ${ }^{3}$ and \\ Alfonso Alonso-Benito ${ }^{1}$ D \\ 1 Departamento de Física, Universidad de La Laguna, 38200 San Cristóbal de La Laguna, Spain; \\ marbelo@ull.es (M.A.); aaloben@ull.es (A.A.-B.) \\ 2 Remote Sensing Working Group, Institute of Computer Science, University of Osnabrück, \\ 49090 Osnabrück, Germany; bjoern.waske@uni-osnabrueck.de \\ 3 Departamento de Informática, Universidad of Almería, 04120 Almería, Spain; jaruiz@ual.es \\ * Correspondence: fmarchet@ull.es
}

Received: 18 September 2019; Accepted: 29 October 2019; Published: 31 October 2019

check for updates

\begin{abstract}
This study analyzes the potential of very high resolution (VHR) remote sensing images and extended morphological profiles for mapping Chestnut stands on Tenerife Island (Canary Islands, Spain). Regarding their relevance for ecosystem services in the region (cultural and provisioning services) the public sector demand up-to-date information on chestnut and a simple straight-forward approach is presented in this study. We used two VHR WorldView images (March and May 2015) to cover different phenological phases. Moreover, we included spatial information in the classification process by extended morphological profiles (EMPs). Random forest is used for the classification process and we analyzed the impact of the bi-temporal information as well as of the spatial information on the classification accuracies. The detailed accuracy assessment clearly reveals the benefit of bi-temporal VHR WorldView images and spatial information, derived by EMPs, in terms of the mapping accuracy. The bi-temporal classification outperforms or at least performs equally well when compared to the classification accuracies achieved by the mono-temporal data. The inclusion of spatial information by EMPs further increases the classification accuracy by $5 \%$ and reduces the quantity and allocation disagreements on the final map. Overall the new proposed classification strategy proves useful for mapping chestnut stands in a heterogeneous and complex landscape, such as the municipality of La Orotava, Tenerife.
\end{abstract}

Keywords: WorldView; bi-temporal image; extended morphological profiles; random forest; Canary Islands

\section{Introduction}

Global environmental changes are affecting ecosystems and ecosystem services at a global, regional and local scale. Therefore, monitoring the conservation status of habitats is important for environmental management and surveying compliance of several multilateral environmental treaties, with an aim to protect the habitats. In order to preserve the most important natural habitats of wild fauna and flora in Europe, the European Union member States decided, by Directive 92/43/EEC (known as the Habitats Directive) of May 1992, to create the Natura 2000 network. One such is the 9260 habitat-Forest vegetation with Castanea sativa Mill. (chestnut woods). In Europe, this habitat is present in more than 600 Natura 2000 sites [1] and occupies an area of approximately 2.5 million hectares, mainly in countries such as France, Italy, Spain, Portugal, Switzerland and Greece, with a great cultural tradition linked to sweet chestnut trees, where rural populations have benefited from the services that this species generates for hundreds of years [2,3]. The conservation status of this habitat in Europe may be 
deemed unfavourable or inadequate, i.e., it requires a change in management or policy in order to bring it back to a favourable position, but there is no danger of it disappearing in the foreseeable future. However, in some regions including the mainland Spain, it is under serious pressure. In regions like the Macaronesian biogeographical region, including the Canary Islands (Spain), up-to-date information for this type of habitat is scarce and do not allow for a proper assessment of its conservation status. The fragmented distribution of chestnut trees in the Canary Islands and the importance that this species has had for the Canarian population as a primary cultural and agricultural resource, confer great scientific value on the chestnut trees and grant the need for its conservation. This is of vital importance today, when the decline in rural population is causing its maintenance and exploitation to be abandoned.

Several projects and studies have been developed at European level to map the distribution and habitat of forest tree species [4], including the species Castanea Sativa Mill. [5,6]. However, none of them include the Macaronesian region (such as the Canary Islands). Given these facts, the generation of up-to-date land use and land cover maps, focusing on chestnut trees, seems necessary. The most recent work on mapping chestnut in the Canary Islands was made in 2008 for the island of Tenerife [7], funded by the Centro de Conservación de la Biodiversidad Agrícola de Tenerife (CCBAT). In this survey, which is based on extensive fieldwork over 1.5 years, a total area of 1374 ha of Chestnut was estimated, with 280 ha within the municipality of La Orotava in the North of Tenerife [7]. While the results are highly precise, an annual evaluation of the state of conservation of this habitat is unfeasible due to the costly and time-consuming field work.

However, remote sensing provides frequent temporal and spatial information on land cover and it is, thus, an efficient tool for monitoring large areas cost-effectively. Satellite remote sensing has been previously used to support surveying compliance, e.g., in the context of Natura 2000 [8], and has successfully been used for mapping various types of vegetation [9-11], including chestnuts trees [12].

The accuracy of a land cover map is affected, amongst other factors, by the classification algorithm and the availability of remote sensing data, and nowadays users can choose between several widely accepted algorithms, as well as diverse remote sensing datasets. As confirmed in different previous studies $[13,14]$ very high-resolution (VHR) images from recent satellite systems are particularly interesting for mapping individual vegetation and tree species at a small scale. VHR multispectral images, e.g., provided by Worldview-2 (WV-2) and WorldView-3 (WV-3), with spatial resolutions of less than $1.8 \mathrm{~m}$ in eight spectral bands, as compared to the usual four-band satellite range, have shown great potential for mapping different vegetation species [15-20]. For example, Immitzer et al. [21] used WV-2 satellite data to classify 10 tree species in a temperate forest in Austria, obtaining an overall accuracy of $82 \%$. Pu et al. [22] mapped seven tree species in the urban city of Tampa (FL, USA) by means of WV-2 and IKONOS images, and they found a better average accuracy of $16-18 \%$ when using WV-2 imagery in comparison to IKONOS data. Reference [23] also showed the efficient performance of WV-2 and WV-3 to classify six commercial forest species in South Africa, obtaining an overall accuracy of $85 \%$. AlMaazmi et al. [24] classified palm trees in the United Arab Emirates (UAE) with WV-3, with a satisfactory overall accuracy of $89 \%$.

Besides high spatial resolution, multitemporal images can acquire data across different phenological vegetation phases and thus, can enhance the separability of classes, which are hard to differentiate with a single image. For example, Tigges et al. [25] used multitemporal images acquired from different phenological seasons by RapidEye to classify eight common trees in the city of Berlin. The increase of spectral information from multitemporal images allowed them to obtain a final classification with an overall accuracy of over 85\%. Li et al. [20] used an object-based classification with WV-2 and WV-3 images for two different areas in China to show that bi-temporal images provided results $10 \%$ higher than individual images. Hill et al. [26], using five Airborne Thematic Mapper images to classify tree species with phenological differences, found the highest overall accuracy of $88 \%$ through the combination of three images. Voss et al. [27] studied seasonal effects in an urban area classification. They compared the summer and autumn classification results for seven different plants showing a low overall accuracy classification (56-57\%) and a greater difference between seasonal results, depending 
on the species under consideration. Additionally, Tarantino et al. [28] used multiseasonal WV-2 images to classify Ailanthus altissima (Mill.) Swingle, an invasive plant species in a protected area in the South of Italy, showing a high overall accuracy value (91\%) for the classification. Lastly, a study with high resolution multi-temporal images allowed the monitoring and detection of chestnut trees phytosanitary problems in the region of Padrela (Portugal) [29].

Besides the use of multitemporal images, classification accuracy was improved by spectral-spatial classification in many studies. In this sense, it is worth noting that both -the multitemporal as well as the spatial information- can increase classification accuracy, e.g., [30]. Object-based image analysis is widely used with diverse remote sensing data and in different study sites [31,32]. Although the definition of adequate image segmentation parameters can be (semi) automated, parameter selection has a significant impact on the classification accuracy [30]. Another development in the context of spectral-spatial classification of remote sensing data is the use of mathematical morphology and morphological profiles (MP) [33], which have been used in various applications and seem particularly interesting for classifying VHR imagery. Although many studies in this context aim on mapping urban areas [34,35], MPs were successfully used for mapping palm trees in VHR GeoEye images [36] and crown delineation in a diverse tropical forest using WV-2 images [37].

The main objective of the presented study is to map chestnut stands in the municipality of La Orotava, on Tenerife (Canary Islands, Spain), using VHR multispectral imagery and mathematical morphology. The specific aims are: (i) to evaluate the general potential of WV-2 and WV-3 satellite imagery to map chestnut stands (ii) to analyse the advantage of using bi-temporal images in regard to the mapping accuracy, and (iii) to assess the impact of extended morphological profiles on the overall accuracy of the final maps.

\section{Materials and Methods}

\subsection{Study Area}

The study area is located in the municipality of La Orotava, in the northern slope of the island of Tenerife, in the Canary Islands a Spanish archipelago near the north-western coast of Africa (Figure 1). Altitude ranges between 600 and 1300 meters above the sea level and the covered area is about 917.6 ha. Climatic conditions are typical of the North of the island of Tenerife, with high relative humidity (70-100\%) due to the influence of NE trade winds, and mild temperatures throughout the year, approximately between $8{ }^{\circ} \mathrm{C}$ and $20^{\circ} \mathrm{C}$, as recorded by the two meteorological stations of the Cabildo de Tenerife in the study area (see [38]), creating a perfect habitat for the development of chestnut trees. The study area is characterised by a strong incline and great spatial variability. The landscape is defined by several roads, country roads, houses, arable plots of various shapes and sizes, many fruit trees, especially apple trees, pear trees, avocado trees, citrus and plum trees, cereal, potato and legume crops, vineyards, and fallow plots. On the left and central parts of the study area (Figure 1a), there is a mix of roads, disperse buildings and agricultural terraced plots with chestnut trees located in the middle of those arable lands, at the edge of roads and close to other species of fruit trees. Conversely, the right side is characterised by a great forest of chestnut trees, which are surrounded by Canarian pine trees (Pinus canariensis), "fayas" or firetrees (Morella faya) and heath shrubs (Erica arborea) (Figure 2). Some isolated specimens are located in ravines that are difficult to access. Chestnut trees in the study area can reach $35 \mathrm{~m}$ in height and they have large bright green leaves during the hottest months of the year (May to September), which fall in the colder months (October to April). This important characteristic could be decisive in identifying and distinguishing this species from others. 


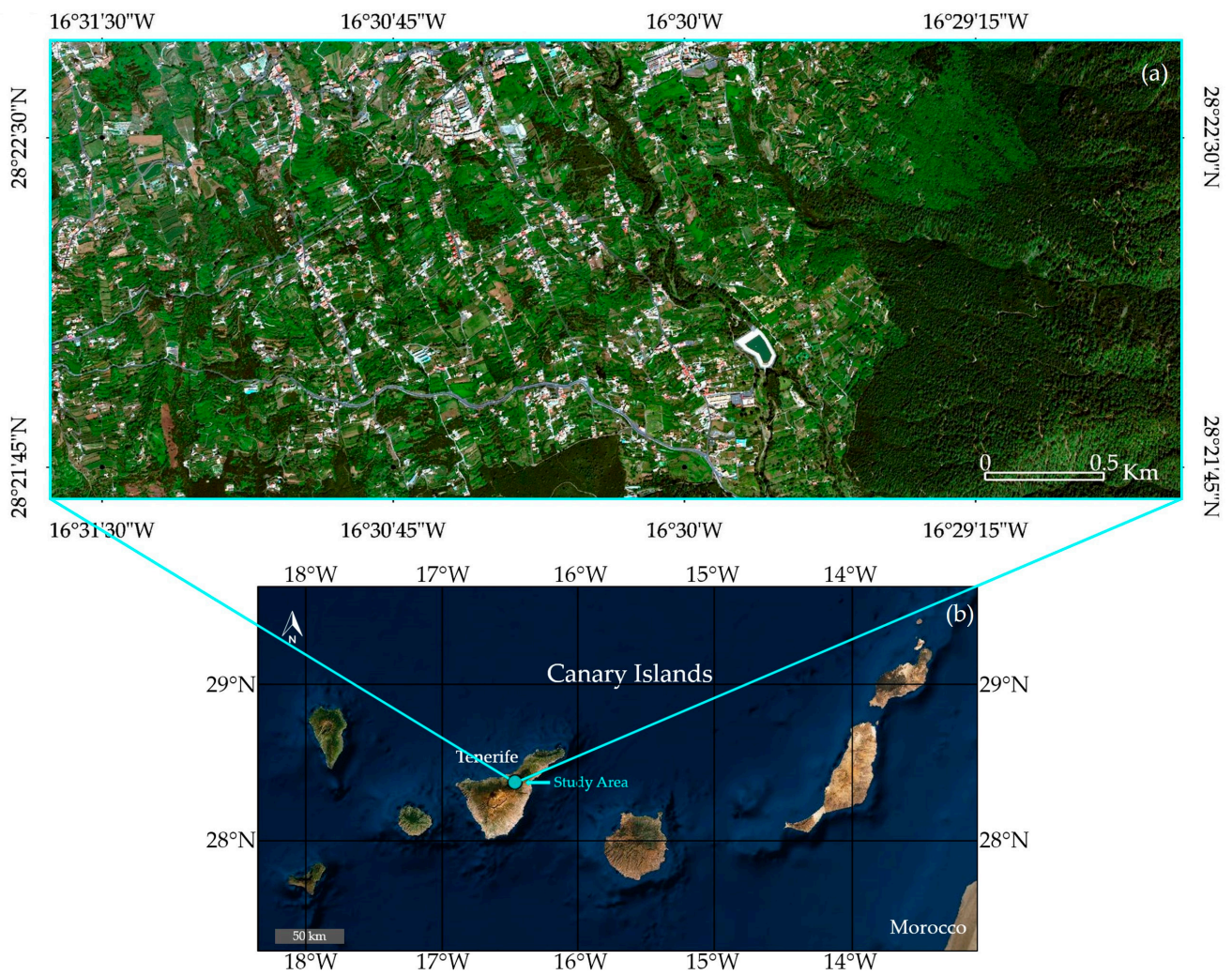

Figure 1. (a) WorldView-3 true colour image of 10 May 2015, demarcating the study area under the coordinates $28^{\circ} 22^{\prime} 43.16^{\prime \prime} \mathrm{N}, 16^{\circ} 31^{\prime} 38.21^{\prime \prime} \mathrm{W}$ (top-left corner) and $28^{\circ} 21^{\prime} 42.53^{\prime \prime} \mathrm{N}, 16^{\circ} 28^{\prime} 42.38^{\prime \prime} \mathrm{W}$ (bottom-right corner); (b) Archipelago of the Canary Islands, the light blue point shows the study area in Tenerife.

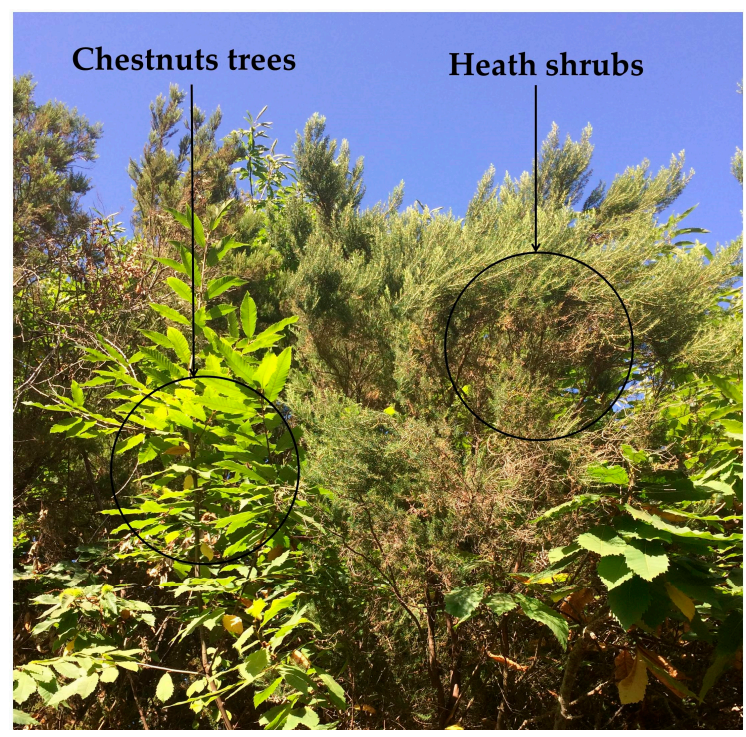

Figure 2. Chestnuts trees in the study area mixed with heath shrubs.

\subsection{Field Data}

Seven thematic classes were defined within the study area based on the available cartographic information provided by [39]: chestnut trees (class of interest); urban areas, including streets, roads and buildings; natural vegetation containing wild vegetation, "fayas", heath shrubs and Canarian pine trees; arable lands that may include potato crops, vineyards, fallow plots, legume and cereal 
crops; citrus and avocado trees; deciduous fruit trees such as apple trees, pear trees and plum trees; and water. Considering the complex characteristics of the study area, both owing to its spatial variability and heterogeneity and to its orography, a visual aerial photo interpretation was conducted to randomly select a certain number of sample points within each class. These orthophotos are obtained annually by [39] from photogrammetric flights. They are corrected by the application of support and aero triangulation processes to represent an orthogonal projection without perspective effects, with spatial resolutions ranging from 10 to $25 \mathrm{~cm}$. The number of plots for each thematic class was chosen quasi-proportional to class extent [40] according to the crop map of years 2007-2008 (https://www.gobiernodecanarias.org/agricultura/agricultura/temas/mapa_cultivos/), except for the urban areas thematic class, due to the high variability of the materials used for its construction as asphalt, cement, uralite, plastic or tiles for roofs, stone, ceramics, etc.

Following this, extensive fieldwork was carried out in the time between the first image in March 2015 and May 2015 (second image) to check and georeference the previously selected plots using the orthophotos. A Global Positioning System (GPS) GeoXT of the GeoExplorer 2008 series connected to an antenna, to improve signal reception in situations under the tree canopy, was used. No differential correction was applied. Geographic coordinates of all the measurements obtained on-site were taken and considered as the main focus of each of the plots that were subsequently identified in the WV images. Plots of each thematic class were defined as polygons of different size (few square meters) containing a variable number of homogeneous pixels. In the case of the trees under study, depending on the shape and appearance of each specimen, the defined polygon may not be square. We were not able to check the class in the field in some parts of the study area, which were difficult to access due to the presence of ravines or steep slopes. We complemented the fieldwork with the orthophotos for 16 plots of natural vegetation and 18 of chestnuts trees. In total, 893 plots were obtained (Table 1) and divided into training and validation data by a simple random sampling [40] at a later stage.

Table 1. Training and validation plots for the various thematic classes selected within the study area.

\begin{tabular}{ccccc}
\hline Thematic Class & $\begin{array}{c}\text { Number of } \\
\text { Training Plots }\end{array}$ & $\begin{array}{c}\text { Total Training } \\
\text { Area }\left(\mathbf{m}^{\mathbf{2}}\right)\end{array}$ & $\begin{array}{c}\text { Number of } \\
\text { Validation Plots }\end{array}$ & $\begin{array}{c}\text { Total Validation } \\
\text { Area } \mathbf{( m}^{\mathbf{2}} \mathbf{)}\end{array}$ \\
\hline Chestnuts trees & 87 & 1131.5 & 94 & 1108.5 \\
Urban areas & 122 & 1968.6 & 137 & 1889.3 \\
Natural vegetation & 75 & 1013.8 & 100 & 1118.7 \\
Arable lands & 54 & 1584.6 & 90 & 1361.9 \\
Citrus and Avocados & 22 & 289.3 & 37 & 271.4 \\
Deciduous fruit trees & 25 & 931.8 & 40 & 975.4 \\
Water & 5 & 40.9 & 5 & 46.1 \\
\hline
\end{tabular}

\subsection{WorldView Images}

Two OrthoReady Standard 2A WorldView satellite images were used in this study. One WorldView-2 (WV-2) image from 12 March 2015 with a spatial resolution of $1.85 \mathrm{~m}$, and a second image from 10 May 2015 acquired by the sensor on board of the WorldView-3 satellite (WV-3) with a spatial resolution of $1.24 \mathrm{~m}$. The choice of these dates was made to better discriminate the two different phenological periods of chestnut trees. The WV-2 satellite launched on 8 October 2009 records high-resolution data with a swath width of $16.4 \mathrm{~km}$ and a maximum revisit period of 1.1 days. The WV-2 has 8 different multispectral bands from visible to near-infrared (NIR) regions of the spectrum (Table 2) [41]. The WV-3 satellite, in orbit since 13 August 2014, has the same multispectral spectral bands of WV-2 (Table 2) and new SWIR and CAVIS (Clouds, Aerosols, Vapors, Ice, and Snow) bands not used in this work. It operates at an altitude of $617 \mathrm{~km}$ and has an average revisit time of less than 1 day, with the ability to collect up to $680,000 \mathrm{~km}^{2}$ per day [41]. 
Table 2. 8 Visible-NIR multispectral bands of WV-2 coincident with WV-3 [41].

\begin{tabular}{ccccc}
\hline \multirow{2}{*}{ Band Name } & \multicolumn{2}{c}{ Spectral Band (nm) } & \multicolumn{2}{c}{ Nominal Spatial Resolution (m) } \\
\cline { 2 - 5 } & WV-2 & WV-3 & WV-2 & WV-3 \\
\hline Coastal & $400-450$ & $400-450$ & 1.84 & 1.24 \\
Blue & $450-510$ & $450-510$ & & \\
Green & $510-580$ & $510-580$ & & \\
Yellow & $585-625$ & $585-625$ & & \\
Red & $630-690$ & $630-690$ & & \\
Red edge & $705-745$ & $705-745$ & & \\
NIR-1 & $760-900$ & $770-895$ & & \\
NIR-2 & $860-1040$ & $860-1040$ & & \\
\hline
\end{tabular}

WV-2 and WV-3 images were atmospherically corrected using the radiative transfer model Fast Line-of-sight Atmospheric Analysis of Spectral Hypercubes (FLAASH) [42]. The input atmospheric parameters used in this model were derived from the vertical profiles of temperature and humidity obtained, in the same days of the satellite images, from Agencia Estatal de Meteorología de España (AEMET) radio-soundings located in Güimar $(28.47 \mathrm{~N}$; $16.38 \mathrm{~W}$ ) (Tenerife) belonging to the World Meteorological Organization (WMO), and the Aerosol Optical Depth retrieved from the AErosol RObotic NETwork (AERONET). Both images were orthorectified using a Digital Terrain Model with $5 \times 5 \mathrm{~m}$ spatial resolution [43]. Subsequently, the two images (March and May) were geometrically co-registered to obtain a unique bi-temporal dataset with 16 bands ( 8 of WV-2 plus 8 of WV-3) at a final spatial resolution of $1.6 \mathrm{~m}$.

\subsection{Methodology}

\subsubsection{Overview on the Classification Framework}

Figure 3 shows the methodology framework used for this study. After the preprocessing of the remote sensing imagery (see Section 2.3) three data sets were generated, consisting in the March image, the May image and a bi-temporal data set, containing both images (i.e., with 16 bands). EMPs are usually applied on a reduced dataset.

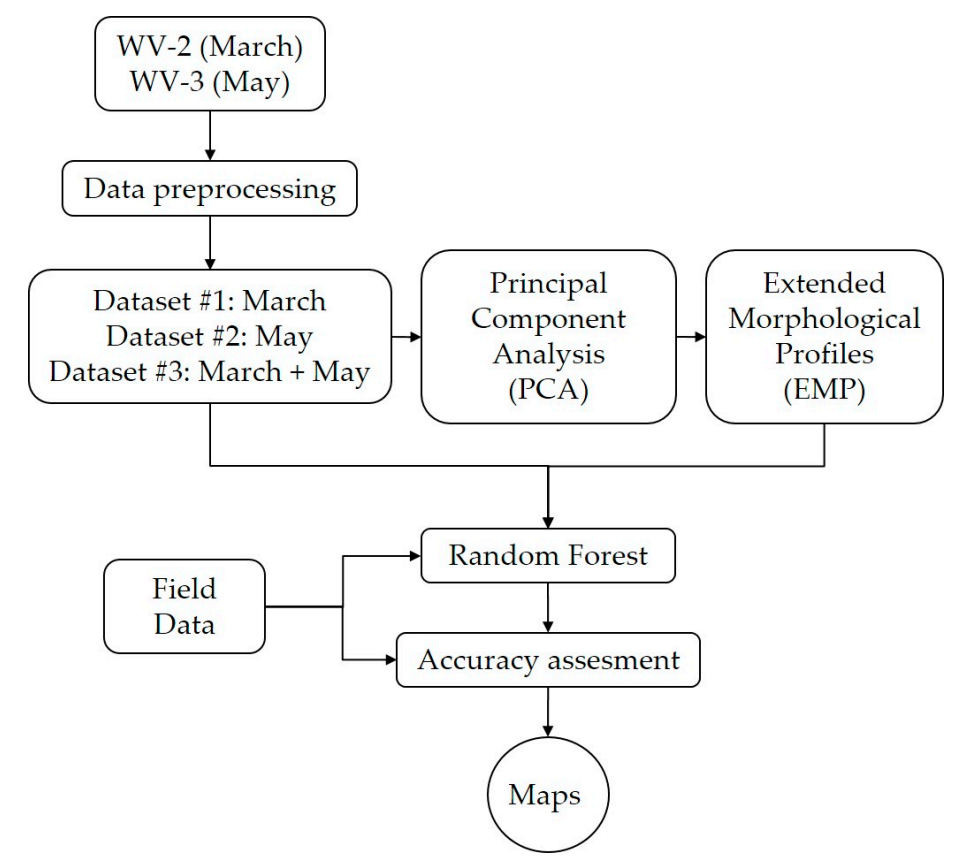

Figure 3. The methodology framework of the study. 
Although various methods for data reduction can be applied [44], we follow the Principal Component Analysis (PCA), which is widely used in this context. Afterwards EMPs are generated for each data set, resulting in three additional data sets, from now on referring to as "March_EMP", "May_EMP", and "Bi-temporal_EMP". A meticulous fieldwork ensured collection of reference data in the study area to train and validate the classification algorithm (see Section 2.2). The algorithm applied was Random Forest (RF). For each classification, the overall accuracy, quantity and allocation disagreements were estimated [45]. Each step is described in detail below.

\subsubsection{Extended Morphological Profile (EMP)}

Morphological profiles are a basic method frequently used for image segmentation, which works by detecting the edges of the objects. Depending on the area of interest, the classification of small size objects could be very difficult, so those profiles provide more information to the image allowing for a better distinction of the class of interest in the classification. Advantageous uses of mathematical morphology for spectral-spatial analysis and classifications are already discussed in several studies [33,34,46,47]. Mathematical morphology is based on the two basic operators: erosion and dilation, which are applied to an image with a set of a known shape, the so-called structuring element (SE). The commonly used morphological operators are opening, which dilate an eroded image, and closing, which erode a dilated image [34,47]. Filtering through reconstruction is normally used, showing a better shape preservation than common morphological filters. Whereas opening isolates bright objects, closing isolates objects in the image that are darker than their surroundings. The a-priori definition of the SE size is usually not available and the so-called (Extended) Morphological Profiles (EMP) are often generated [33]. An MP consists of opening and closing generated with a SE of a fixed shape in different sizes. Instead of applying morphological filters to the original bands, feature subspaces are frequently used to reduce the dimensionality, e.g., Principal Component Analysis (PCA) [35,48]. The PCA makes it possible to select only the most important information contained in the bands of the image considering new dataset, where the first principal component accounts for the most variability in the data and each succeeding component accounts for the remaining variability [49]. Following [48], a PCA was applied before the morphological filtering to both images (March, May) and to the bi-temporal datasets. Only the first three components were selected, because they explained at least $91 \%$ of the images' variance. Besides the dimensionality reduction, principal components of a higher order tend to show noise and provide very little information. A disk-shaped SE with five different sizes was applied to the three first principal components. Consequently, 30 additional feature bands were generated for each dataset result by applying five opening filters and five closing filters (Figure 4).

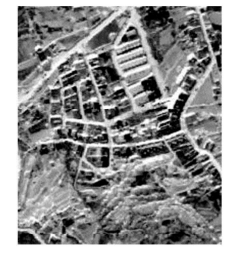

PCA1

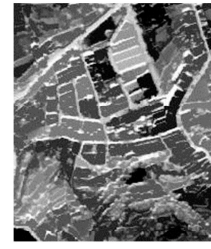

CL1

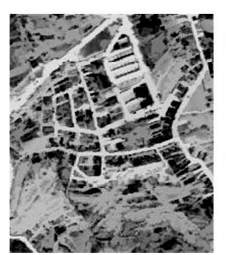

OP1

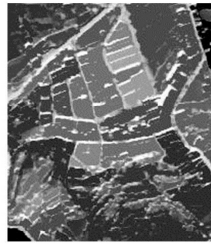

CL2

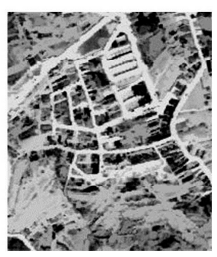

OP2

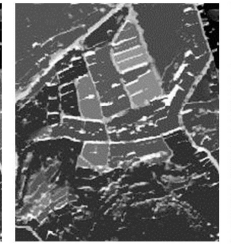

CL3

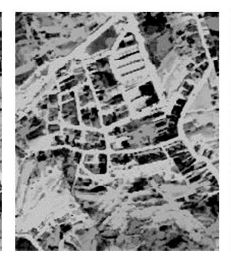

OP3

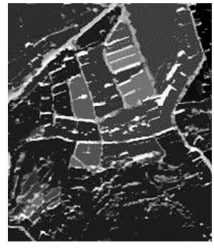

CL4

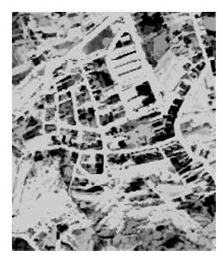

OP4

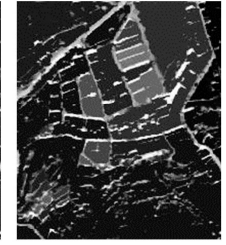

CL5

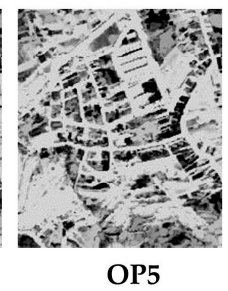

Figure 4. The effect of each filter applied to the original PCA1. Five closing (CL) and five opening (OP) attributes are shown. 
The final datasets consisted of 38 bands ( $8 \mathrm{WV}$ bands +30 feature bands) for the March and May images and 46 bands ( $16 \mathrm{WV}$ bands +30 feature bands) for the bi-temporal image, respectively named Mar_EMP, May_EMP and Bi-temporal_EMP.

\subsubsection{Classification Algorithm}

Random Forest (RF) algorithm was selected to classify all datasets (i.e., March, May, Bi-temporal, March_EMP, May_EMP and Bi-temporal_EMP). RF was originally developed by [50] and introduced by [51] in context of remote sensing. It is a machine learning algorithm that shows many advantages when compared to other methods: only a few input parameters are required, the training and classification process is fast, it allows for the use of categorical and unbalanced data or missing values [51]. RF is especially suitable for high dimensional data [52,53] and hyperspectral data [21,54]. Many studies have proven this algorithm's high performance [55-58]. The principal parameter, which must be defined in order to execute the classification, is the number of decision trees $\left(n_{\text {tree }}\right)$. We used the machine learning RF embedded in the EnMap Box [59]. Several studies have shown that a $\mathrm{n}_{\text {tree }}=500$ ensures the maximum accuracy $[20,60]$, therefore, for this study we decided to use this value for each WV image.

\subsubsection{Accuracy Assessment}

In order to assess the accuracy of the resulting maps, the error matrix for each classification (March, May and Bi-temporal and March_EMP, May_EMP and Bi-temporal_EMP) was calculated. Following the Pontius and Millones's method [45], overall accuracy (OA), Quantity (Qd) and Allocation (Ad) disagreements were estimated for each classification. Qd were used to find the difference between reference and classified maps due to imperfect matching in class proportions. Qd allows to discriminate if a particular classification algorithm is not able to detect correctly the number of selected classes. Allocation disagreement indicates the differences between the validation data and the final map considering the spatial distribution. It shows whether the algorithm mistakes the place of the classes during the classification. Validation data were used to assess the classifications of all images. The application of these measures of disagreement, $\mathrm{Qd}$ and $\mathrm{Ad}$, to evaluate the accuracy of the final classifications is a common practice in many works [61-64] and has been applied to the same area of study for the mapping of forest fuels $[65,66]$.

\section{Results}

Overall accuracy values of the classifications for each of the datasets under consideration, including the $95 \%$ confidence interval (\%), are shown in Table 3.

Table 3. Overall accuracy (\%) with the 95\% confidence interval (\%).

\begin{tabular}{cc}
\hline Dataset & Overall Accuracy [\%] \\
\hline March & $80.38 \pm 1.50$ \\
May & $66.65 \pm 1.78$ \\
Bi-temporal & $82.12 \pm 1.44$ \\
Mar_EMP & $83.86 \pm 1.36$ \\
May_EMP & $71.53 \pm 1.73$ \\
Bi-temporal_EMP & $85.26 \pm 1.27$ \\
\hline
\end{tabular}

The highest overall accuracy value is provided by the Bi-temporal_EMP $(85.26 \%)$, whereas the worst result is that of the May image (66.65\%). Although the use of the bi-temporal data set, improves classification accuracy, these differences are statistically non-significant. In contrast to this the use of the EMP increases all overall accuracies, resulting in a statistically significant improvement. The use of morphological filters (i.e., EMP) improves the classification accuracies, up to $5 \%$ when compared to the accuracies achieved on the May image. Although the classification of the bi-temporal dataset 
is already relatively high, the accuracy is increased by the EMP (up to $~ 3 \%$ ). These seemingly small differences may be considered as significant, as there is no intersection between intervals with $95 \%$ of confidence for each of the sets and their equivalent with EMP (Table 2).

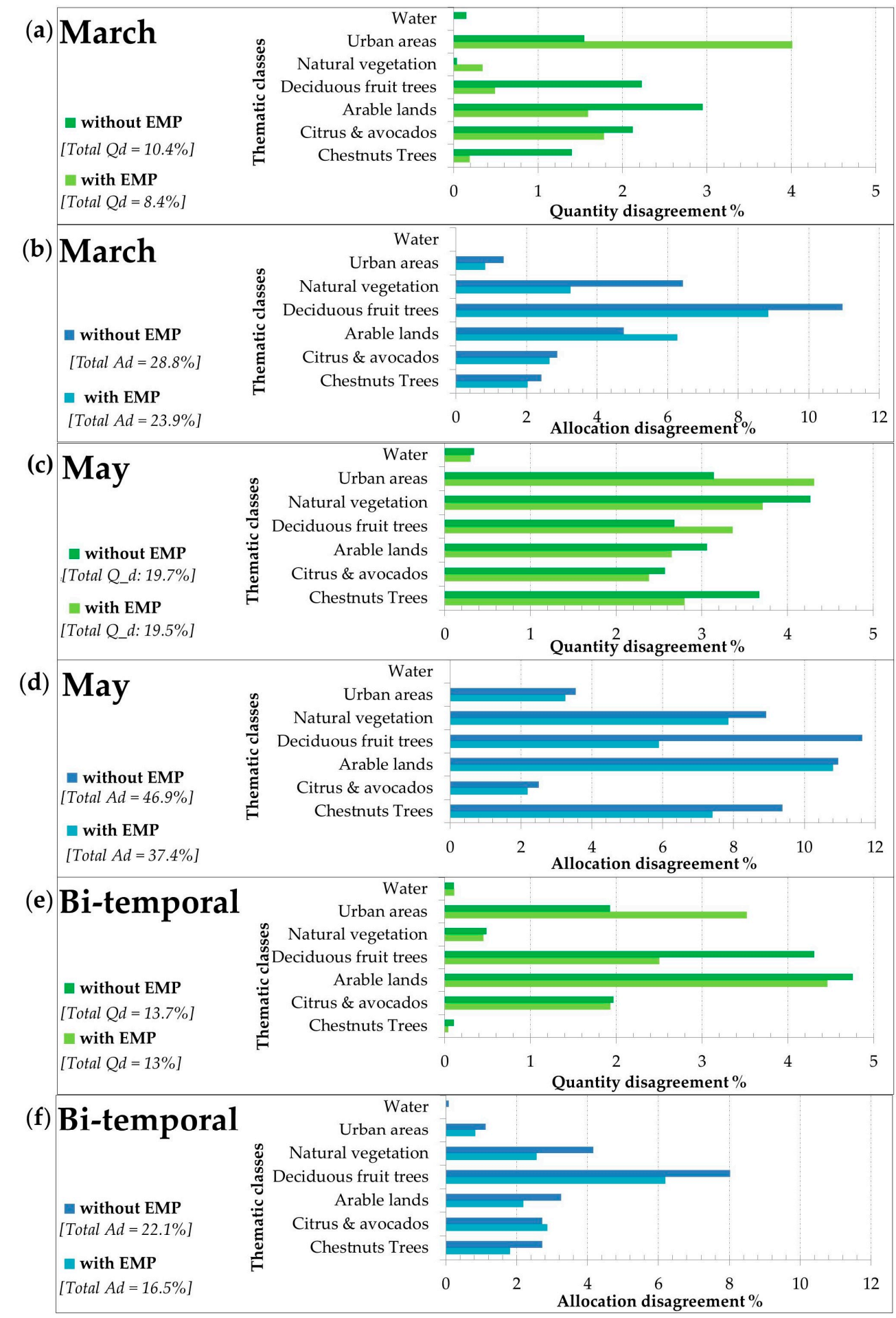

Figure 5. (a) March and March_EMP Qd (\%). (b) March and March_EMP Ad (\%). (c) May and May_EMP Qd (\%). (d) May and May_EMP Ad (\%). (e) Bi-temporal and Bi-temporal_EMP Qd (\%). (f) Bi-temporal and Bi-temporal_EMP Ad (\%). 
Total Qd and Ad disagreements were estimated as the summation of the disagreements by quantity and allocation of all thematic classes. Irrespectively of the classified data set and thematic classes, total Ad is larger than total Qd (see Figure 5). For the March image, the total Qd and Ad are $10.4 \%$ and $28.8 \%$, respectively. For chestnut trees, the main class of interest, an allocation error of $2.4 \%$ was found, while there is a $1.4 \%$ quantity error. The classification accuracy of the May image is much lower, when compared to the March image, resulting in higher Qd and Ad (e.g., for chestnut Qd $=19.7 \%$ and $\mathrm{Ad}=46.9 \%$ ). A detailed analysis (Figure 5) underlines the confusion between the vegetation classes, except for citrus and avocado, the allocation errors ranging exceed $9 \%$. The classification of chestnut trees results in a quantity error of $3.7 \%$ and allocation error of $9.4 \%$, which is higher when compared to the results obtained with the March image. As the overall classification accuracy increased by the classification of the bi-temporal dataset, Ad and Qd decreases in most of the cases. The detailed accuracy assessment reveals that the total allocation disagreement is the smallest, with a $22.1 \%$ value, while, the total Qd slightly worsens ( $3 \%)$ in regard to March.

Besides the positive impact of the bi-temporal data, the class-wise accuracy assessment confirms the positive impact of the EMP on the classification accuracy. Almost all results are improved by the use of EMPs. When evaluating the Mar_EMP image, the total allocation error is reduced down to 5\%. For its part, the chestnut trees class also shows better results, with allocation and quantity errors of $2 \%$ and $0.2 \%$, respectively. Therefore, chestnut trees become one of the best identified classes, alongside water, whose errors are theoretically zero. The use of EMPs also decreases the total Ad for the May image up to $9.5 \%$, although their application is hardly noticeable in the total Qd, the chestnut trees class once again benefiting the most with an error decrease of almost $1 \%$. Overall, it is worth mentioning that the use of EMPs and bi-temporal data provide the most accurate map. Total allocation error decreases by $5.6 \%$ as compared to the Bi-temporal image and the chestnut trees class produces the fewer allocation $(1.8 \%)$ and quantity $(0.04 \%)$ errors, in comparison to the remaining classified datasets. By the same token, natural vegetation also shows the smallest quantity and allocation errors, $0.45 \%$ and $2.6 \%$, respectively. The deciduous fruit trees class shows the highest allocation error $(6.2 \%)$, whereas the arable lands class is the one where the largest quantity error (4.5\%) is made. Both the urban class and the water class guarantee allocation errors under $0.8 \%$.

Figure 6 shows the most and less accurate maps, obtained by the classification of the (a) bi-temporal dataset with EMP and (b) the May image. The visual assessment of these maps confirms the previous findings and general good performance of the bi-temporal data and the EMP. Although the classification of the May image shows the general structures of the study area, confusion between classes is obvious (e.g., between natural vegetation and chestnut trees). The map appears noisy even in homogenous areas and sometimes it is hard to assign the correct land cover type to a plot. Consequently, the classification of the May image results in the lowest overall accuracy and highest disagreement values (see Table 2 and Figure 5). When comparing the map with the classification result achieved on Bi-temporal_EMP, it can be seen that many pixels are misclassified as chestnut trees in an area, which is dominated by natural vegetation (eastern part of the study site). In the western part, great confusion amongst the deciduous fruit tree class, natural vegetation and some citrus and avocado tree plots, identified as arable lands, can be observed. 


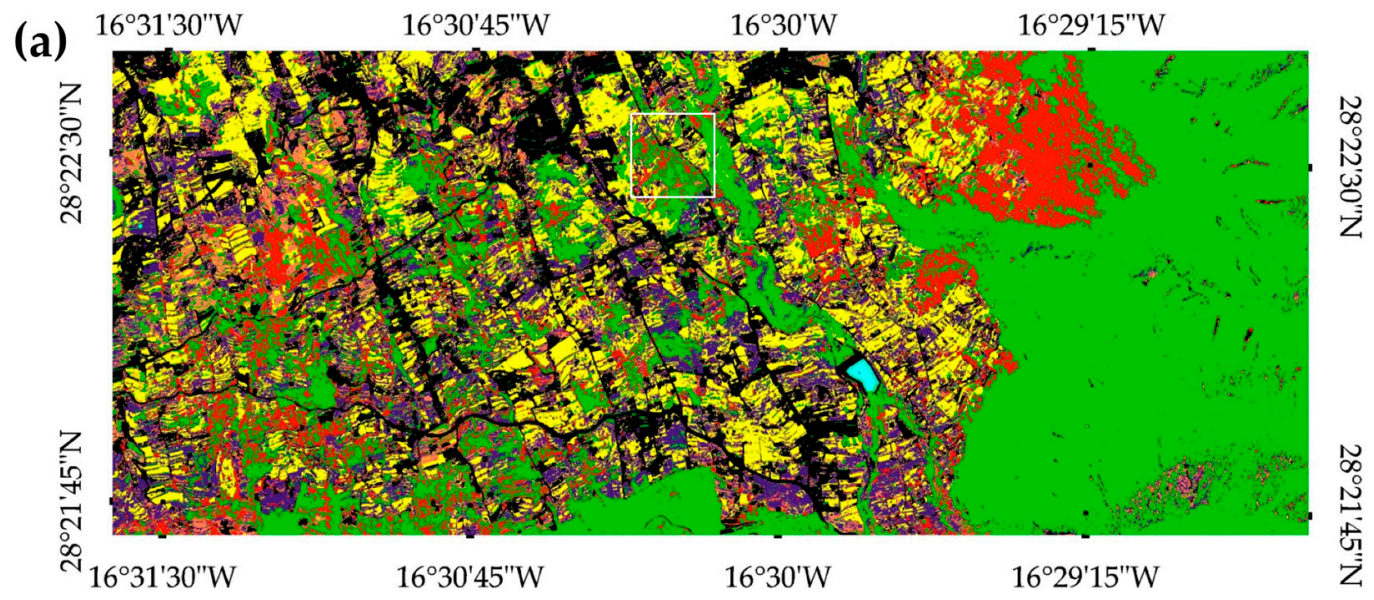

(b)
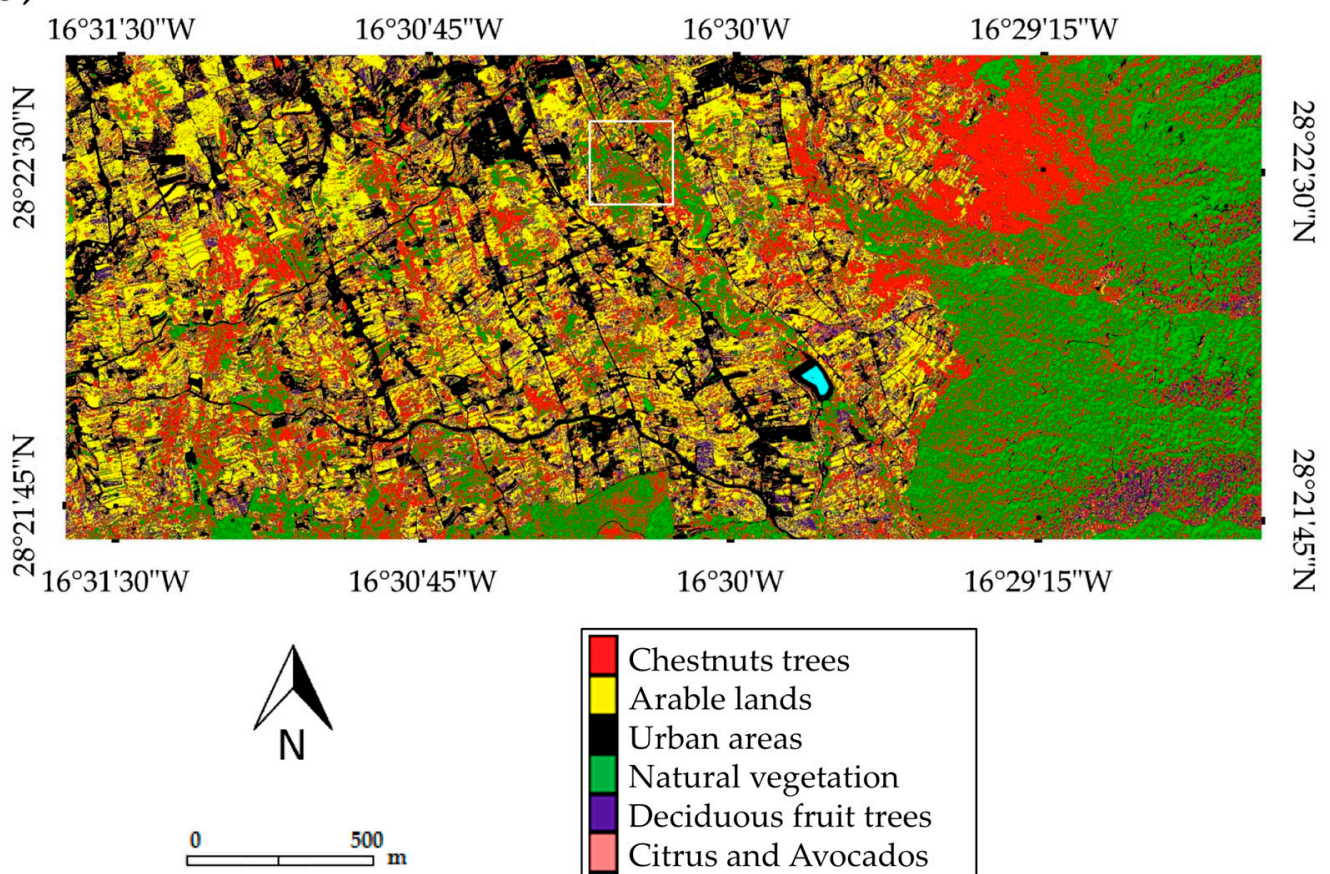

Chestnuts trees

Arable lands

Urban areas

Natural vegetation

Deciduous fruit trees

Citrus and Avocados

Water

Figure 6. (a) Bi-temporal_EMP classified with RF. (b) May without EMP image classified with RF.

In general these drawbacks are significantly reduced by using bi-temporal data and EMPs. The noise is clearly reduced and most areas can be assigned properly to a specific class. Edges along natural objects can be more clearly identified. Nevertheless some noise is still inherent.

A subset $\left(28^{\circ} 22^{\prime} 35.75^{\prime \prime} \mathrm{N}, 16^{\circ} 30^{\prime} 22.21^{\prime \prime} \mathrm{W} ; 28^{\circ} 22^{\prime} 25.49^{\prime \prime} \mathrm{N}, 16^{\circ} 30^{\prime} 10.32^{\prime \prime} \mathrm{W}\right)$ indicated by the white square is shown in Figure 7. 


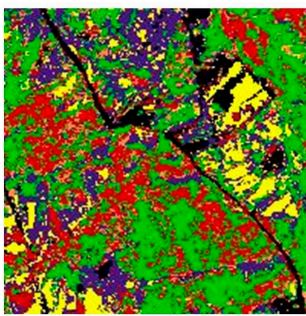

(a)

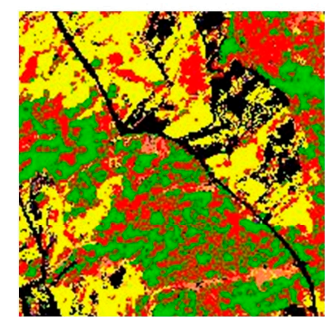

(e)

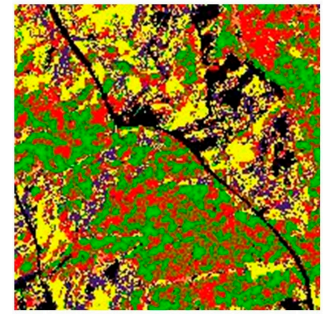

(b)

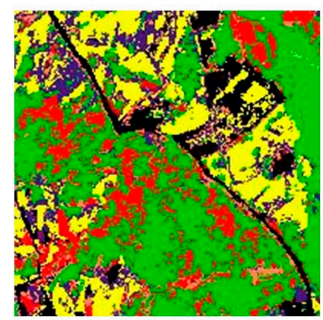

(f)

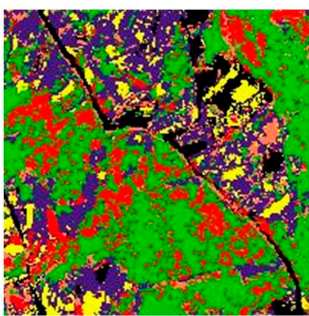

(c)

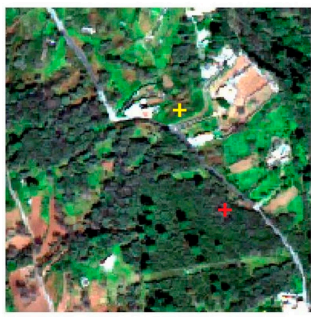

(g)

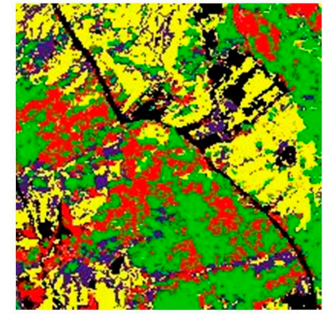

(d)

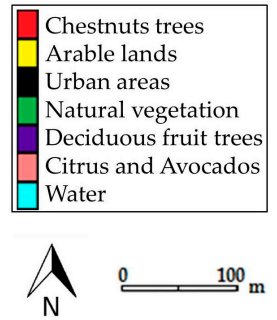

$\mathrm{N} \stackrel{100}{\longleftarrow} \mathrm{m}$

Figure 7. A zoomed-in image ( $\left.28^{\circ} 22^{\prime} 35.75^{\prime \prime} \mathrm{N}, 16^{\circ} 30^{\prime} 22.21^{\prime \prime} \mathrm{W} ; 28^{\circ} 22^{\prime} 25.49^{\prime \prime} \mathrm{N}, 16^{\circ} 30^{\prime} 10.32^{\prime \prime} \mathrm{W}\right)$ of the study area classified with RF: (a) March, (b) May, (c) Bi-temporal, (d) Mar_EMP, (e) May_EMP, (f) Bi-temporal_EMP, (g) True colour image of 12 March 2015. The two crosses show the validation plots in this portion of the study area: in yellow for arable lands and in red for chestnut trees.

The benefits of EMP are clearly shown by a visual comparison of the Figure $7 \mathrm{~d}-\mathrm{f}$, with the original image (Figure 7g). Differences are especially evident for the May datasets (Figure $7 \mathrm{~b}, \mathrm{e}$ ), where the salt and pepper effect in the map is decreased by using the EMP. Furthermore the distribution of the thematic classes in the classifications with EMP appears more similar to each other than the original images with a noticeable reduction in the deciduous trees class. Chestnuts trees class has a spatial distribution and covered area quite similar between Bi-temporal and Bi-temporal_EMP, while a strong difference is visible for the same class comparing May (Figure 7b) and May_EMP (Figure 7e). The classification of the original images without EMP (Figure 7a,b) show an overestimate of chestnuts trees, which not appear in the bi-temporal datasets. In regard to the others classes, Figure 7a,c show an apparently correct spatial distribution of natural vegetation, but a wrong distribution of deciduous fruit trees, which are confused with arable lands. In Figure $7 \mathrm{~b}$,e (May datasets), arable lands are overestimate and incorrectly distributed. Finally, can be emphasized that March_EMP and Bi-temporal_EMP are the images whose appearance is more similar, according to the previous results (e.g., chestnuts trees).

Lastly, the covered area was estimated for each thematic class by the dataset providing the best results (Bi-temporal_EMP). The largest area is covered by natural vegetation, with 363 ha, followed by the urban areas (151 ha). Deciduous fruit trees and arable lands take up almost the same area (130 ha and 140 ha respectively), while citrus and avocado cover only 47 ha. Regarding the interest class, the covered area estimated is 84 ha. The water class, on the other hand, seems to occupy 0.9 ha, including all reservoirs of various sizes holding water, mainly for agricultural purposes, within the study area. However, and despite the latter seemingly being the best classified class, given that it shows the lowest allocation and quantity errors, its estimated area appears to be greater than what was observed in the previous fieldwork and the aerial orthophotos. In fact, as Figure 8 shows, there are shadow pixels that have been classified as water, providing for an overestimation of the total area covered by this thematic class. This error can be attributed to the fact that the spectral signature of the shadows is characterised by much smaller spectral values as compared to other classes, making the algorithm wrongly identify these pixels. 
(a)

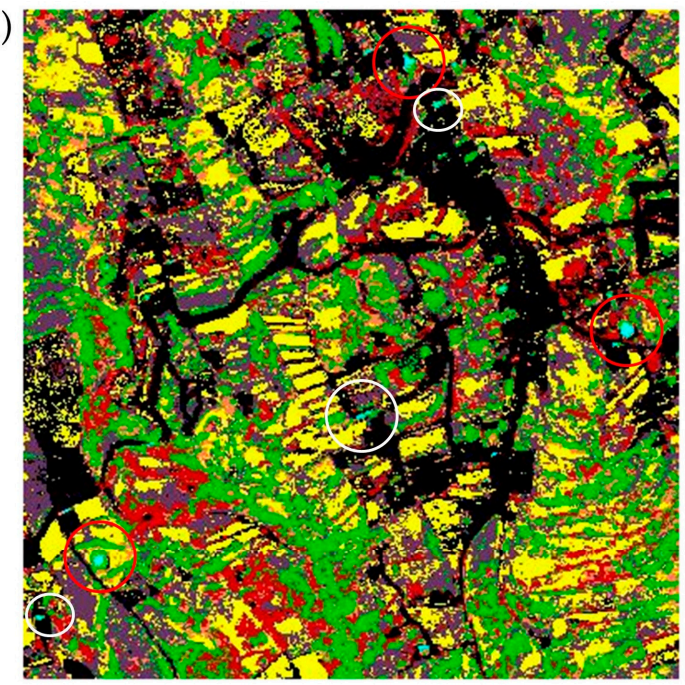

(b)

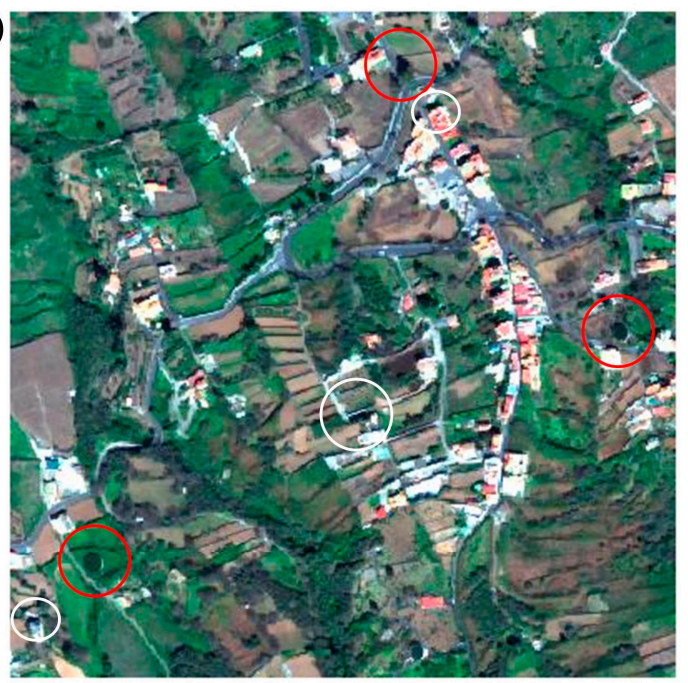

Figure 8. A zoomed-in $\left(28^{\circ} 22^{\prime} 43.39^{\prime \prime} \mathrm{N}, 16^{\circ} 31^{\prime} 17.69^{\prime \prime} \mathrm{W} ; 28^{\circ} 22^{\prime} 20.68^{\prime \prime} \mathrm{N}, 16^{\circ} 30^{\prime} 54.38^{\prime \prime} \mathrm{W}\right)$ of the study area showing shadows (white circles) and reservoirs pixels (red circles) classified as water class.

(a) Bi-temporal_EMP classified image; (b) True colour image of 12 March 2015.

\section{Discussion}

The results obtained in this work underline the benefits offered by the simultaneous use of a very high spatial resolution bi-temporal image and spatial information, which was extracted by extended morphological profiles (EMPs). The two images captured by the WorldView satellites, separated in time by approximately two months and, therefore, gathering two completely different phenological states of the chestnut trees, allow us to improve the classification OA by up to $18 \%$. This is in accordance to previous studies, which discuss the impact of multitemporal data on the classification accuracy in context of land cover mapping [20,26-28].

The positive impact of EMPs by incorporating spatial and spectral information into the classification process is also proven EMPs were built using the spectral characteristics extracted from the original images by analysing the principal components. As in previous studies [34,67], classification accuracy significantly increased in comparison to the "simple" spectral classification. The accuracy assessment reveals significant differences in all cases when comparing datasets with and without EMPs. However, when the three datasets with EMPs are analysed in detail, it should be underlined that difference in the overall accuracy between March_EMP and Bi-temporal_EMP is not significant. It is worth to underline that the accuracy achieved with the May image is clearly lower when compared to the March and bi-temporal data set. Undoubtedly, this shows the enormous difficulty of the method when classifying the May image, against any other containing information from the month of March. The similar spectral response of certain thematic classes, such as natural vegetation sprouting in the springtime in many abandoned plots, and the fully-leafed and flowered chestnut trees in the month of May, but not in March; the agricultural areas with different crops depending on the time of the year: potatoes with the plant's foliage reaching its maximum vegetative growth in May just before the usual harvest month of June; similarly, vineyards, which hardly show new growth in March due to the recent pruning in February, are full of leaves in May; fruit trees, especially pear trees, but also apple and plum trees, with vegetative cycles that are similar to that of the chestnut tree, create further confusion in the algorithm for the classification process.

It is interesting to analyse the results from previous studies in which the use of multitemporal images improves the classification results regarding the use of a single date, as is the case in this particular study. Li et al. [20] compared the results provided by the Support-Vector-Machine (SVM) and Random Forest algorithms by applying them to individual WV-2 and WV-3 images and a bi-temporal composition of these. Their goal was to identify various species of urban trees (Paulownia tomentosa, 
Populus tomentosa Carrière, Sophora japonica, Ginkgo biloba, Platanus acerifolia) in two study areas in Beijing (China), namely, Capital Normal University (CNU) and Beijing Normal University (BNU). Their results show an improvement of $10 \%$ to $20 \%$ in the OA through the use of the bi-temporal image, which is in agreement with the results of our study of approximately $15 \%$ of improvement when comparing the May image to the Bi-temporal one. Tigges et al. [25] for their part, in a classification of several tree species (Pinus, Aesculus, Platanus, Tilia, Acer, Populus and Fagus), typical in the urban vegetation of Berlin (Germany), also obtained a better result using a bi-temporal image generated by the RapidEye satellite. In this case, the multitemporal image allowed them to increase spectral information and to improve the overall applying the SVM algorithm.

In addition to using bi-temporal data, applying methods that take the extraction of the morphological characteristics from the images into account makes it possible to obtain thematic maps with more spatial information [47,68-70]. The thematic maps obtained in this study, based on the original data, present the general structures in the classified area but seem very noisy, showing the typical salt-and-pepper effect (Figure 6b) due to the lack of spatial information in the pre-classification stage [71]. This disadvantage is clearly reduced when applying morphological profiles, which produced a more homogeneous final classified image (Figure 6a), consistent with the results previously obtained [69]. The use of MPs has been typically applied to hyperspectral images [34,44,67]. For instance, Dalla Mura et al. [35] applied morphological attribute profiles (APs) to two different datasets: an image with 102 spectral bands from the city centre of Pavia (Italy) and another image acquired over an area of the University in the same city, made up of 103 bands. By using APs, they were able to increase the accuracy from $2 \%$ for the city area up to $10 \%$ for the University. In our study, due to having multispectral (WV-2 and WV-3) rather than hyperspectral images, we have built MPs using the method that appears to work best in these cases [68], as the Extended Morphological Profiles suggest. Despite MPs being built differently, this work also shows improvements between 3\% for the bi-temporal set and nearly $5 \%$ for the May image. All of the above presumes the good performance of this approach using WV-2 and WV-3 bi-temporal images.

As previously discussed, there are no significant differences for the two sets of images showing the best results in terms of overall accuracy (March_EMP and Bi-temporal_EMP) and, accordingly, we do not have of a valid criterion to choose one above the other dataset in principle. However, when comparing both classifications regarding the allocation and quantity disagreements estimations, the differences became apparent. An analysis of the above error components allows for a detailed comparison of the results of the classifications, for each one of them provides different information. Depending on the specific goals of each study, as well as the WV images and the budget available, both for acquiring them and for the fieldwork, it will be more important to have access to thematic maps where errors are minimised by allocation in some cases, and by quantity in other cases. Generally speaking, if the intent is to estimate the area covered (ha) by each one of the thematic classes, the March_EMP dataset, with a total Qd of $8.4 \%$, would be the best option. By contrast, if the main objective was to find out the exact location of the various classes, then the Bi-temporal_EMP would be the appropriate image to guarantee the best results, with a total Ad of $16.5 \%$. In both cases, the effect of EMP morphological profiles always ensures a reduction of both the Ad and the Qd. Nevertheless, it is especially remarkable for allocation disagreements, with improvements up to $9.5 \%$ in comparison to the greater reduction produced for the March image Qd (2\%).

On the whole, including the EMPs in the classification process with RF correctly models the original images spatial information, making it possible to generate better thematic maps in all instances. Results obtained globally (across all thematic classes) are also consistent with the purpose initially outlined in this study: updating the map of chestnut tree (class of interest) in a rural area in the North of the island of Tenerife. The image providing the lesser quantity $(0.1 \%)$ and allocation ( $1.8 \%)$ errors, as well as the greater overall accuracy $(85.26 \%)$, was Bi-temporal_EMP. We should not, however, dismiss the option that March allows to obtain a classification, at least for the chestnut tree class of interest, 
with equivalent results ( $\mathrm{Qd}=0.2 \%$ and $\mathrm{Ad}=2 \%$ ), especially if it was only possible to obtain one WorldView (2 or 3 ) image per year.

While in general the use of bi- and multitemporal image analysis, morphological filters, and the RF classifier are not new methodologies in the remote sensing community, the combination is innovative and proves useful in terms of the mapping accuracy. Morphological filters (i.e., EMPs) have been mainly applied to mono-temporal multispectral images (including UAV data), panchromatic images and hyperspectral imagery. However, the use of EMPS mapping specific vegetation species with VHR bi-temporal multispectral space-borne imagery is limited.

The general findings and proposed methods are also interesting in context of other applications and study sites. In various studies the use of multitemporal as well as spatial information proves useful for an accurate discrimination of individual classes. Random forest are able to handle diverse (e.g., multitemporal multispectral images and spatial information) as well as high-dimensional data sets. A pre-selection of specific acquisitions seems not-necessary and the analyst can use all available images. Moreover, EMPs consist of several opening and closing operations, with increasing kernel size, the specific definition of one single kernel size seems not necessary. The use can simply define a broad range of filter sizes and the random forest classifier can handle the resulting high-dimensional feature space. Moreover morphological filters and random forest are available in diverse also freely available, software packages. As the methods are relatively simple to use and only require minimum user interaction, the used classification strategy can be simply applied to diverse study sites and applications.

A regular land cover monitoring (e.g., performing chestnuts mapping in regular intervals), requires training data for each time interval, e.g., for each year, which is highly costly and often unfeasible. The simplest approach would be to use the previously trained classifier. However in most of the cases this does not provide reliable maps, due differences in the atmospheric conditions, different number of acquisitions, changes in phenology etc. However, this is not a limitation of the proposed method and affects all supervised classifications. To overcome this limitation, transfer learning techniques have been introduced in remote sensing (e.g., [72]). In [73] inter-annual land cover changes were mapped, using a pair of multi-spectral images and a change detection based transfer learning approach. After identifying areas where land cover has changed between the two years, the changed areas were reclassified by a supervised classifier, using pixels from the unchanged areas of the first map as training data. This concept could be easily used to extend the mapping strategy proposed in our study, and thus enable a regular monitoring of chestnuts stands.

\section{Conclusions}

In this study, we investigate the potential for bi-temporal VHR data and extended morphological profiles (EMPs) for land cover mapping in a highly diverse and spatial complex study site on Tenerife. The specific objective was to map supra-Mediterranean and sub-Mediterranean chestnut-dominated forests (Castanea Sativa Mill.), also known as Habitat 9260 in context of EU Habitat directive. Regarding surveying compliances, which require a regular monitoring of the habitat status, we aimed on simple and straightforward classification method.

The new approach is based on a supervised classification of bi-temporal data and morphological profiles, using Random Forests. As expected both, the use of bi-temporal information as well as the inclusion of spatial information by mathematical morphology proves useful in terms of the mapping accuracy. The methods are relatively simple to use and only require minimum user interaction. Therefore the approach seems also interesting in context of operational monitoring and non-expert users. While this study is based on commercial VHR data the use of public available imagery data seems also interesting (e.g., Sentinel-2). Moreover, classifiers such as Random Forest are able to handle large and diverse data sets. Overall the approach is adequate for operational monitoring systems and large scale applications. 
Author Contributions: F.M., B.W. and M.A. conceived and designed the methodology; F.M. applied the methodology and obtained the results. All authors analyzed and discussed the results. F.M. in collaboration with the rest of authors wrote and contributed to the editing of the manuscript.

Funding: The Universidad de La Laguna and the Universidad de Almería funded this work through the bridge projects 2018/0001440 and 2019/006, granted in the 2018 and 2019 calls. This study was also partially funded by the Ministerio de Ciencia, Innovación y Universidades (MCIU), the Agencia Estatal de Investigación (AEI) and the Fondo Europeo de Desarrollo Regional (FEDER) through the project RTI2018-099171-B-I00.

Acknowledgments: We wish to thank the three anonymous peer reviewers for their valuable comments and suggestions.

Conflicts of Interest: The authors declare no conflict of interest.

\section{References}

1. European Environment Agency. Factsheet for Castanea Sativa Woods-EUNI. Available online: https: //eunis.eea.europa.eu/habitats/10210\#sites (accessed on 23 September 2018).

2. Roces-Diaz, J.V.; Díaz-Varela, E.R.; Barrio-Anta, M.; Álvarez-Álvarez, P. Sweet chestnut agroforestry systems in North-western Spain: Classification, spatial distribution and an ecosystem services assessment. For. Syst. 2018, 27, e03S. [CrossRef]

3. Lorenzo, S.P.; Díaz, G.; María, A.; Cabrer, R.; Hernández, J.Z.; Rodríguez, R.L.; González, J.G. Los Castañeros de Canarias; CCBAT-CAP: Tenerife, Spain, 2007; pp. 9-13.

4. De Rigo, D.; Caudullo, G.; Houston Durrant, T.; San-Miguel-Ayanz, J. The European Atlas of Forest Tree Species: Modelling, data andinformation on forest tree species. In European Atlas of Forest Tree Species; San-Miguel-Ayanz, J., de Rigo, D., Caudullo, G., Houston Durrant, T., Mauri, A., Eds.; Publication Office of the European Union: Luxembourg, 2016; pp. 40-45.

5. Conedera, M.; Tinner, W.; Krebs, P.; de Rigo, D.; Caudullo, G. Castanea sativa in Europe: Distribution, habitat, usage and threats. In European Atlas of Forest Tree Species; San-Miguel-Ayanz, J., de Rigo, D., Caudullo, G., Houston Durrant, T., Mauri, A., Eds.; Publication Office of the European Union: Luxembourg, 2016; pp. 78-79.

6. Conedera, M.; Krebs, P.; Tinner, W.; Pradella, M.; Torriani, D. The cultivation of Castanea sativa (Mill.) in Europe, from its origin to its diffusion on a continental scale. Veg. Hist. Archaeobot. 2004, 13, 161-179. [CrossRef]

7. Hernandez Gonzalez, J.Z.; Rios Mesa, D.J.; Celorrio Dorta, G. El Castañero en Tenerife. Estudio de la Situación del Cultivo Mediante el Uso de Sistemas de Información Geográfica; Cabildo Insular de Tenerife: Tenerife, Spain, 2008; pp. 10-25.

8. Corbane, C.; Lang, S.; Pipkins, K.; Alleaume, S.; Deshayes, M.; García Millán, V.E.; Strasser, T.; Vanden Borre, J.; Toon, S.; Michael, F. Remote sensing for mapping natural habitats and their conservation status-New opportunities and challenges. Int. J. Appl. Earth Obs. Geoinf. 2015, 37, 7-16. [CrossRef]

9. Asner, G.P.; Jones, M.O.; Martin, R.E.; Knapp, D.E.; Hughes, R.F. Remote sensing of native and invasive species in Hawaiian forests. Remote Sens. Environ. 2008, 112, 1912-1926. [CrossRef]

10. Oldeland, J.; Dorigo, W.; Wesuls, D.; Jürgens, N. Mapping Bush Encroaching Species by Seasonal Differences in Hyperspectral Imagery. Remote Sens. 2010, 2, 1416-1438. [CrossRef]

11. Waske, B.; Benediktsson, J.; Sveinsson, J. Random Forest Classification of Remote Sensing Data. In Signal and Image Processing for Remote Sensing, 2nd ed.; CRC Press: Boca Raton, FL, USA, 2012.

12. Marques, P.; Pádua, L.; Adão, T.; Hruška, J.; Peres, E.; Sousa, A.; Sousa, J.J. UAV-Based Automatic Detection and Monitoring of Chestnut Trees. Remote Sens. 2019, 11, 855. [CrossRef]

13. Nagendra, H.; Rocchini, D. High resolution satellite imagery for tropical biodiversity studies: The devil is in the detail. Biodivers. Conserv. 2008, 17, 3431-3442. [CrossRef]

14. Cho, M.A.; Mathieu, R.; Asner, G.P.; Naidoo, L.; van Aardt, J.; Ramoelo, A.; Debba, P.; Wessels, K.; Main, R.; Smit, I.P.J.; et al. Mapping tree species composition in South African savannas using an integrated airborne spectral and LiDAR system. Remote Sens. Environ. 2012, 125, 214-226. [CrossRef]

15. Mustafa, Y.T.; Habeeb, H.N. Object based technique for delineating and mapping 15 tree species using VHR WorldView-2 imagery. In Proceedings of the Remote Sensing for Agriculture, Ecosystems, and Hydrology XVI, Amsterdam, The Netherlands, 22-25 September 2014; Neale, C.M.U., Maltese, A., Eds.; SPIE: Bellingham, WA, USA, 2014; Volume 9239, p. 92390G. 
16. Waser, L.T.; Küchler, M.; Jütte, K.; Stampfer, T. Evaluating the potential of worldview-2 data to classify tree species and different levels of ash mortality. Remote Sens. 2014, 6, 4515-4545. [CrossRef]

17. Madonsela, S.; Cho, M.; Mathieu, R.; Mutanga, O.; Ramoelo, A.; Kaszta, Ż.; Van De Kerchove, R.; Wolff, E. Multi-phenology WorldView-2 imagery improves remote sensing of savannah tree species. Int. J. Appl. Earth Obs. Geoinf. 2017, 58, 65-73. [CrossRef]

18. Wu, H.; Levin, N.; Seabrook, L.; Moore, B.; McAlpine, C. Mapping Foliar Nutrition Using WorldView-3 and WorldView-2 to Assess Koala Habitat Suitability. Remote Sens. 2019, 11, 215. [CrossRef]

19. Ghosh, A.; Joshi, P.K. A comparison of selected classification algorithms for mappingbamboo patches in lower Gangetic plains using very high resolution WorldView 2 imagery. Int. J. Appl. Earth Obs. Geoinf. 2014, 26, 298-311. [CrossRef]

20. Li, D.; Ke, Y.; Gong, H.; Li, X. Object-Based Urban Tree Species Classification Using Bi-temporal WorldView-2 and WorldView-3 Images. Remote Sens. 2015, 7, 16917-16937. [CrossRef]

21. Immitzer, M.; Atzberger, C.; Koukal, T. Tree Species Classification with Random Forest Using Very High Spatial Resolution 8-Band WorldView-2 Satellite Data. Remote Sens. 2012, 4, 2661-2693. [CrossRef]

22. Pu, R.; Landry, S. A comparative analysis of high spatial resolution IKONOS and WorldView-2 imagery for mapping urban tree species. Remote Sens. Environ. 2012, 124, 516-533. [CrossRef]

23. Peerbhay, K.Y.; Mutanga, O.; Ismail, R. Investigating the Capability of Few Strategically Placed Worldview-2 Multispectral Bands to Discriminate Forest Species in KwaZulu-Natal, South Africa. IEEE J. Sel. Top. Appl. Earth Obs. Remote Sens. 2014, 7, 307-316. [CrossRef]

24. AlMaazmi, A. Palm trees detecting and counting from high-resolution WorldView-3 satellite images in United Arab Emirates. In Proceedings of the Remote Sensing for Agriculture, Ecosystems, and Hydrology, Berlin, Germany, 10-13 September 2018; Neale, C.M., Maltese, A., Eds.; SPIE: Bellingham, WA, USA, 2018; p. 61.

25. Tigges, J.; Lakes, T.; Hostert, P. Urban vegetation classification: Benefits of multitemporal RapidEye satellite data. Remote Sens. Environ. 2013, 136, 66-75. [CrossRef]

26. Hill, R.A.; Wilson, A.K.; George, M.; Hinsley, S.A. Mapping tree species in temperate deciduous woodland using time-series multi-spectral data. Appl. Veg. Sci. 2010, 13, 86-99. [CrossRef]

27. Voss, M.; Sugumaran, R. Seasonal Effect on Tree Species Classification in an Urban Environment Using Hyperspectral Data, LiDAR, and an Object-Oriented Approach. Sensors 2008, 8, 3020-3036. [CrossRef]

28. Tarantino, C.; Casella, F.; Adamo, M.; Lucas, R.; Beierkuhnlein, C.; Blonda, P. Ailanthus altissima mapping from multi-temporal very high resolution satellite images. ISPRS J. Photogramm. Remote Sens. 2019, 147, 90-103. [CrossRef]

29. Pádua, L.; Hruška, J.; Bessa, J.; Adão, T.; Martins, L.M.; Gonçalves, J.A.; Peres, E.; Sousa, A.M.R.; Castro, J.P.; Sousa, J.J. Multi-Temporal Analysis of Forestry and Coastal Environments Using UASs. Remote Sens. 2018, 10, 24. [CrossRef]

30. Stefanski, J.; Mack, B.; Waske, O. Optimization of Object-Based Image Analysis with Random Forests for Land Cover Mapping. IEEE J. Sel. Top. Appl. Earth Obs. Remote Sens. 2013, 6, 2492-2504. [CrossRef]

31. Blaschke, T. Object based image analysis for remote sensing. ISPRS J. Photogramm. Remote Sens. 2010, 65, 2-16. [CrossRef]

32. Chemura, A.; van Duren, I.; van Leeuwen, L.M. Determination of the age of oil palm from crown projection area detected from WorldView-2 multispectral remote sensing data: The case of Ejisu-Juaben district, Ghana. ISPRS J. Photogramm. Remote Sens. 2015, 100, 118-127. [CrossRef]

33. Benediktsson, J.A.; Pesaresi, M.; Arnason, K. Classification and feature extraction for remote sensing images from urban areas based on morphological transformations. IEEE Trans. Geosci. Remote Sens. 2003, 41, 1940-1949. [CrossRef]

34. Fauvel, M.; Benediktsson, J.A.; Chanussot, J.; Sveinsson, J.R. Spectral and Spatial Classification of Hyperspectral Data Using SVMs and Morphological Profiles. IEEE Trans. Geosci. Remote Sens. 2008, 46, 3804-3814. [CrossRef]

35. Dalla Mura, M.; Atli Benediktsson, J.; Waske, B.; Bruzzone, L. Extended profiles with morphological attribute filters for the analysis of hyperspectral data. Int. J. Remote Sens. 2010, 31, 5975-5991. [CrossRef]

36. Dos Santos, A.M.; Mitja, D.; Delaître, E.; Demagistri, L.; de Souza Miranda, I.; Libourel, T.; Petit, M. Estimating babassu palm density using automatic palm tree detection with very high spatial resolution satellite images. J. Environ. Manag. 2017, 193, 40-51. [CrossRef] 
37. Wagner, F.H.; Ferreira, M.P.; Sanchez, A.; Hirye, M.C.M.; Zortea, M.; Gloor, E.; Phillips, O.L.; de Souza Filho, C.R.; Shimabukuro, Y.E.; Aragão, L.E.O.C. Individual tree crown delineation in a highly diverse tropical forest using very high resolution satellite images. ISPRS J. Photogramm. Remote Sens. 2018, 145, 362-377. [CrossRef]

38. AgroCabildo. Agricultura y Desarrollo Rural en Tenerife. Available online: http://www.agrocabildo.org/ agrometeorologia_estaciones.asp (accessed on 2 February 2018).

39. GRAFCAN. Mapas de Canarias. Available online: https://www.grafcan.es (accessed on 31 October 2018).

40. Olofsson, P.; Foody, G.M.; Herold, M.; Stehman, S.V.; Woodcock, C.E.; Wulder, M.A. Good practices for estimating area and assessing accuracy of land change. Remote Sens. Environ. 2014, 148, 42-57. [CrossRef]

41. DigitalGlobe. Tools \& Resources. Available online: https://www.digitalglobe.com/resources\#resource-tablesection (accessed on 14 August 2019).

42. Matthew, M.W.; Adler-Golden, S.M.; Berk, A.; Felde, G.; Anderson, G.P.; Gorodetzky, D.; Paswaters, S.; Shippert, M. Atmospheric correction of spectral imagery: Evaluation of the FLAASH algorithm with AVIRIS data. Proc. Appl. Imag. Pattern Recognit. Work. 2002, 2002, 157-163.

43. Gil, A.L.; Núñez-Casillas, L.; Isenburg, M.; Benito, A.A.; Bello, J.J.R.; Arbelo, M. A comparison between LiDAR and photogrammetry digital terrain models in a forest area on Tenerife Island. Can. J. Remote Sens. 2013, 39, 396-409.

44. Castaings, T.; Waske, B.; Atli Benediktsson, J.; Chanussot, J. On the influence of feature reduction for the classification of hyperspectral images based on the extended morphological profile. Int. J. Remote Sens. 2010, 31, 5921-5939. [CrossRef]

45. Pontius, R.G.; Millones, M. Death to Kappa: Birth of quantity disagreement and allocation disagreement for accuracy assessment. Int. J. Remote Sens. 2011, 32, 4407-4429. [CrossRef]

46. Diggle, P.J.; Serra, J. Image Analysis and Mathematical Morphology. Biometrics 1983, 39, 536. [CrossRef]

47. Soille, P.; Pesaresi, M. Advances in mathematical morphology applied to geoscience and remote sensing. IEEE Trans. Geosci. Remote Sens. 2002, 40, 2042-2055. [CrossRef]

48. Benediktsson, J.A.; Palmason, J.A.; Sveinsson, J.R. Classification of hyperspectral data from urban areas based on extended morphological profiles. IEEE Trans. Geosci. Remote Sens. 2005, 43, 480-491. [CrossRef]

49. Abdi, H.; Williams, L.J. Principal component analysis. Wiley Interdiscip. Rev. Comput. Stat. 2010, 2, $433-459$. [CrossRef]

50. Breiman, L. Random Forests. Mach. Learn. 2001, 45, 5-32. [CrossRef]

51. Pal, M. Random forest classifier for remote sensing classification. Int. J. Remote Sens. 2005, 26, $217-222$. [CrossRef]

52. Barrett, B.; Nitze, I.; Green, S.; Cawkwell, F. Assessment of multi-temporal, multi-sensor radar and ancillary spatial data for grasslands monitoring in Ireland using machine learning approaches. Remote Sens. Environ. 2014, 152, 109-124. [CrossRef]

53. Rodriguez-Galiano, V.F.; Ghimire, B.; Rogan, J.; Chica-Olmo, M.; Rigol-Sanchez, J.P. An assessment of the effectiveness of a random forest classifier for land-cover classification. ISPRS J. Photogramm. Remote Sens. 2012, 67, 93-104. [CrossRef]

54. Lawrence, R.L.; Wood, S.D.; Sheley, R.L. Mapping invasive plants using hyperspectral imagery and Breiman Cutler classifications (randomForest). Remote Sens. Environ. 2006, 100, 356-362. [CrossRef]

55. Baccini, A.; Goetz, S.J.; Walker, W.S.; Laporte, N.T.; Sun, M.; Sulla-Menashe, D.; Hackler, J.; Beck, P.S.A.; Dubayah, R.; Friedl, M.A.; et al. Estimated carbon dioxide emissions from tropical deforestation improved by carbon-density maps. Nat. Clim. Chang. 2012, 2, 182-185. [CrossRef]

56. Bekker, D.L.; Thompson, D.R.; Abbey, W.J.; Cabrol, N.A.; Francis, R.; Manatt, K.S.; Ortega, K.F.; Wagstaff, K.L. Field Demonstration of an Instrument Performing Automatic Classification of Geologic Surfaces. Astrobiology 2014, 14, 486-501. [CrossRef] [PubMed]

57. Chan, J.C.-W.; Paelinckx, D. Evaluation of Random Forest and Adaboost tree-based ensemble classification and spectral band selection for ecotope mapping using airborne hyperspectral imagery. Remote Sens. Environ. 2008, 112, 2999-3011. [CrossRef]

58. Debats, S.R.; Luo, D.; Estes, L.D.; Fuchs, T.J.; Caylor, K.K. A generalized computer vision approach to mapping crop fields in heterogeneous agricultural landscapes. Remote Sens. Environ. 2016, 179, $210-221$. [CrossRef]

59. Enmap. Available online: https:/enmap-box.readthedocs.io/en/latest/index.h (accessed on 2 May 2019). 
60. Waske, B.; Braun, M. Classifier ensembles for land cover mapping using multitemporal SAR imagery. ISPRS J. Photogramm. Remote Sens. 2009, 64, 450-457. [CrossRef]

61. Skowno, A.L.; Thompson, M.W.; Hiestermann, J.; Ripley, B.; West, A.G.; Bond, W.J. Woodland expansion in South African grassy biomes based on satellite observations (1990-2013): General patterns and potential drivers. Glob. Chang. Biol. 2017, 23, 2358-2369. [CrossRef]

62. Pickard, B.; Gray, J.; Meentemeyer, R. Comparing Quantity, Allocation and Configuration Accuracy of Multiple Land Change Models. Land 2017, 6, 52. [CrossRef]

63. Warrens, M.J. Properties of the quantity disagreement and the allocation disagreement. Int. J. Remote Sens. 2015, 36, 1439-1446. [CrossRef]

64. Estoque, R.C.; Pontius, R.G.; Murayama, Y.; Hou, H.; Thapa, R.B.; Lasco, R.D.; Villar, M.A. Simultaneous comparison and assessment of eight remotely sensed maps of Philippine forests. Int. J. Appl. Earth Obs. Geoinf. 2018, 67, 123-134. [CrossRef]

65. Alonso-Benito, A.; Arroyo, L.; Arbelo, M.; Hernández-Leal, P. Fusion of WorldView-2 and LiDAR Data to Map Fuel Types in the Canary Islands. Remote Sens. 2016, 8, 669. [CrossRef]

66. Alonso-Benito, A.; Arroyo, L.A.; Arbelo, M.; Hernández-Leal, P.; González-Calvo, A. Pixel and object-based classification approaches for mapping forest fuel types in Tenerife Island from ASTER data. Int. J. Wildl. Fire 2013, 22, 306-317. [CrossRef]

67. Palmason, J.A.; Benediktsson, J.A.; Sveinsson, J.R.; Chanussot, J. Classification of hyperspectral data from urban areas using morpholgical preprocessing and independent component analysis. In Proceedings of the IEEE International Geoscience and Remote Sensing Symposium, Seoul, Korea, 29 July 2005; pp. 176-179.

68. Pesaresi, M.; Benediktsson, J.A. A new approach for the morphological segmentation of high-resolution satellite imagery. IEEE Trans. Geosci. Remote Sens. 2001, 39, 309-320. [CrossRef]

69. Fauvel, M.; Tarabalka, Y.; Benediktsson, J.A.; Chanussot, J.; Tilton, J.C. Advances in Spectral-Spatial Classification of Hyperspectral Images. Proc. IEEE 2013, 101, 652-675. [CrossRef]

70. Fauvel, M.; Chanussot, J.; Benediktsson, J.A. A spatial-spectral kernel-based approach for the classification of remote-sensing images. Pattern Recognit. 2012, 45, 381-392. [CrossRef]

71. Lu, D.; Weng, Q. A survey of image classification methods and techniques for improving classification performance. Int. J. Remote Sens. 2007, 28, 823-870. [CrossRef]

72. Tuia, D.; Persello, C.; Bruzzone, L. Domain adaptation for the classification of RS data: An overview of recent advances. IEEE Geosci. Remote Sens. Mag. 2016, 4, 41-57. [CrossRef]

73. Crowson, M.; Hagensieker, R.; Waske, B. Mapping land cover change in northern Brazil with limited training data. Int. J. Appl. Earth Obs. 2019, 78, 202-214. [CrossRef] 